\title{
ARTE E FILOSOFIA: PARA UMA CRÍTICA DOS IDEAIS ASCÉTICOS ${ }^{1}$
}

Oswaldo Giacoia Jr. (Unicamp) $)^{2}$

ogiacoia@hotmail.com

Resumo: A partir das relações entre arte e filosofia, tal como elas são tratadas no pensamento de Friedrich Nietzsche, o artigo desenvolve uma reflexão sobre a seriedade e o riso, a leveza e a gravidade, para ressaltar a importância da ironia e do humor na crítica de Nietzsche à metafísica e à moral. Neste sentido procura-se apresentar e discutir como Nietzsche desenvolve uma ironia de tipo especial, o expediente para uma "maiêutica do riso". Essa ironia é o que assegura aos 'espíritos livres' a distância crítica que os protege contra a petrificação em convicções derradeiras e definitivas e a tentação dos fundamentos estabelecidos.

Palavras-chave: Arte; filosofia; moral; ironia.

O problema da seriedade (Ernst) talvez seja uma das mais importantes vertentes da filosofia madura nietzscheana. Tanto assim que, na terceira dissertação de Para a Genealogia da Moral, Nietzsche praticamente identifica o sacerdote ascético com a seriedade e o espírito de gravidade:

Somente agora, após avistarmos o sacerdote ascético atacamos seriamente o nosso problema: o que significa o ideal ascético? - agora a coisa fica 'séria': temos o próprio representante da seriedade à nossa

\footnotetext{
${ }^{1}$ Recebido: 09-10-2016/ Aceito: 08-12-2016/ Publicado on-line: 19-01-2017.

${ }^{2}$ Oswaldo Giacoia Jr. é Bolsista de Produtividade em Pesquisa do CNPq - Nível 1B e Professor da Universidade Estadual de Campinas, Campinas, SP, Brasil.
} 
frente. 'Que significa toda seriedade?' - esta pergunta, ainda mais fundamental, aparece já aqui em nossos lábios: uma pergunta para fisiólogos, claro. (NIETZSCHE 1998, p. 106).

A existência sacerdotal é, então, o âmbito de proveniência de modalidade de vida, cuja forma é plasmada em ideais negativos, sobretudo na renúncia e na condenação moral, sintetizados no 'espírito de gravidade', na seriedade dos homini religiosi: eles são, sobretudo, a castidade, a pobreza e a obediência; em outras palavras: a negação da vontade de viver objetividade no próprio corpo, a renúncia à sexualidade e à reprodução e o quebrantamento de si como incondicional submissão a uma regra categórica. Ascese é transitus ascendente para um mundo supra sensível, constituído de realidades inteligíveis, essências eternas, verdadeiras, oposto à impermanência do tempo, ao absurdo da dor, à violência da morte, à potência enganadora da imaginação e das paixões.

Por essa negatividade ínsita, a seriedade, o espírito de gravidade, são, para Nietzsche, as insígnias da vingança e do ressentimento, voltados contra os sentidos, o corpo, a transitoriedade, a dor e a morte, isto é, contra as potências do falso, do transitório, do simulacro, das aparências ilusórias, da insensatez e da desmedida. Dentre as inúmeras passagens sugestivas a esse respeito, destaco a seguinte:

Meu velho demônio e arqui-inimigo, o espírito de gravidade e tudo o que ele criou: coação, estatuto, necessidade, consequência, finalidade, vontade, bem e mal: - Pois não tem de existir aquilo sobre o qual se dance e se ultrapasse dançando? Não têm de existir, em prol dos leves, levíssimos, toupeiras e pesados anões? (NIETZSCHE 2011, p. 188)

Este mesmo espírito transfigura-se também em filosofia 
e ciência, e os arqui-representantes dessa transformação são Sócrates, Platão e Aristóteles. A crítica genealógica da intenção moral (a 'moralina') inerente à história da filosofia ganha impulso a partir da descoberta desse parentesco entre filosofia, ciência, metafísica e ascese religiosa.

Para Nietzsche, a ciência não é um antípoda da ascese, nem se inspira em ideais de outra natureza que os ascéticos; pode-se dizer, até mesmo, que a exigência incondicional de verdade, que é o apanágio da consciência científica honesta, é também a forma mais espiritualizada da sublimação ascética do absoluto e do incondicional, despojada de toda sua vestimenta religiosa. Diferença real em relação à vida ascética só nos é dada na arte:

A arte, na qual justamente a mentira se santifica, a vontade de engano tem a boa consciência de seu lado, é muito mais fundamentalmente antagônica ao ideal ascético do que a ciência: assim o experimentou o instinto de Platão, do maior de todos os inimigos da arte que a Europa produziu até hoje; Platão contra Homero, este é o total, o autêntico antagonismo - lá o homem do além, com a melhor das vontades, o grande caluniador da vida; aqui o seu involuntário divinizador, a dourada natureza. (NIETZSCHE 1980, p. 402)

Nesse sentido, Platão foi sempre o grande adversário e ponto de interrogação para Nietzsche; ele foi, para o psicólogo Nietzsche, o autêntico caso e $a$ vivência fundamental. Todos os seus outros célebres encontros: o apóstolo Paulo, os filósofos Kant, Schopenhauer, Rousseau, o artista Richard Wagner, são variações - casos certamente importantes, mas nem por isso mais do que variantes (abarten) do idealismo dogmático, cujo genial e fatídico inventor foi Platão. Porisso, num supremo esforço de auto-reflexão, ao concluir $\mathrm{O}$ Crespúsculo dos Ídolos - já praticamente às véspe- 
ras do desenlace trágico de sua trajetória intelectual -, Nietzsche atribui ao seu livro anti-socrático de estréia filosófica um peso e um valor extraordinários:

"O 'Nascimento da Tragédia' foi minha primeira transvaloração de todos os valores: com isso retorno novamente ao solo do qual cresce meu querer, meu poder - eu o último discípulo do filósofo Dionysos, - eu, o mestre do eterno retorno [...]" (NIETZSCHE 1980, p. 160). Para poder medir a adequadamente a extensão desse insight, é seria necessário remontar à sua condenação por Platão, no livro III de A República. Como é sabido, quando trata do tema da educação dos guardiões na cidade perfeita, Sócrates considera (República 388 d-e) que os jovens educandos para o exercício dessa importante função na cidade não devem ser "inclinados a rir; de regra, muito riso provoca violentas reações. Não devemos, por conseguinte, admitir que poeta algum nos apresente homens respeitáveis dominados pelo riso, e muito menos os deuses" (PLATÃO 1988, p. 121).

Ora, em nenhum outro aspecto o antiplatonismo de Nietzsche fica tão claro quanto a respeito do riso - o antípoda do espírito de gravidade. $\mathrm{O}$ riso exuberante e intimorato é, segundo Nietzsche, tanto perdulário quanto mortal. "Eu acreditaria somente num deus que soubesse dançar. Quando vi meu diabo, achei-o sério, meticuloso, profundo e solene: era o espírito de gravidade - ele faz todas as coisas caírem. Não com a ira, mas com o riso é que se mata. Eia, vamos matar o espírito de gravidade!" (NIETZSCHE 2011, p. 41). "Mas uma coisa eu sei - e contigo mesmo aprendi uma vez, ó Zaratustra: quem quer matar mais completamente, ri. 'Não com a ira, mas com o riso é que se mata' assim falaste um dia. Ó Zaratustra, homem oculto, aniqui- 
lador sem ira, santo perigoso - és um velhaco!" (NIETZSCHE 2011, p. 299).

$\mathrm{O}$ riso é também purificador e redentor:

Se minha virtude é a virtude de um dançarino, e muitas vezes saltei como s dois pés para um enlevo ouro-esmeralda: Se minha maldade é uma maldade sorridente, que se sente em casa entre roseirais e sebes de lírios: - pois no riso tudo que é mau se acha concentrado, mas santificado e absolvido por sua própria bem-aventurança. (NIETZSCHE 2011, p. 41)

Todos os experimentos e tentativas de auto-superação e de transvaloração de todos os valores, em Nietzsche - muito particularmente sua genealogia da moral e sua crítica do Cristianismo -, são um prolongamento necessário, um aprofundamento, mas também uma forma de consumação da cruzada anti-platônica; dito numa fórmula: transvalorar a transvaloração platônica da moral, levar à auto-supressão a interpretação moralista da existência , por dever de honestidade intelectual é visto por Nietzsche como sua missão em filosofia.

Nietzsche deu a essa tarefa a forma de um programa filosófico, isso ainda antes da publicação de seu primeiro grande livro, O Nascimento da Tragédia. Num fragmento póstumo do final de 1870-abril de 1871, escreve ele: "Minha filosofia: platonismo revertido: quando mais afastado do vedadeiro ente, tanto mais puro, belo, melhor. A vida no brilho da aparência como meta" (NIETZSCHE 1980, p. 199). Por isso, tem razão Duval quando reconhece ser o essencial da filosofia de Nietzsche uma reversão da inversão platônica, uma aposta em Heráclito contra Platão:

"Nietzsche reverte, portanto, a ordem dos valores que Platão tinha instituído entre o conhecimento do que per- 
manece idêntico e o devir: ele considera que a verdade é a realidade do devir e que o conhecimento é uma fonte de erros e ilusões" (DUVAL 1969, p. 627). Não se trata, porém, de uma simples reversão de posições, mas de uma lógica da auto-supressão, em que os valores dominantes na lógica platônica são levados a extrair suas derradeiras conseqüências, para, então, reverterem-se em seu contrário: a verdade em erro, a realidade em aparência, a seriedade em riso.

"Rir de si mesmo, como se deveria rir para faze-lo a partir da verdade inteira - para isso os melhores não tiveram bastante senso de verdade até hoje, e os mais talentosos tiveram pouco gênio! Talvez ainda haja um futuro também para o riso" (NIETZSCHE 2001, p. 52). Esse futuro reservado ao riso na Gaia Ciência aparece como um privilégio dos homens modernos, aqueles que se distinguem pela virtude do sentido histórico; este é também dissipatório e corrosivo, pois dissolve a solidez de todo absoluto pretensamente supra histórico, e faz implodir todo incondicionado. Nós, os eruditos do sentido histórico, somos também aqueles que formamos o bloco carnavalesco da homérica gargalhada:

Mas o 'espírito', em especial, o 'espírito histórico', divisa também uma vantagem nesse desespero: repetidamente, um novo pedaço do passado e do exterior é experimentado, vestido, retirado, guardado, sobretudo estudado - somos a primeira época estudiosa in puncto [em matéria] de 'fantasias', quero dizer, morais, artigos de fé, gostos artísticos e religiões, preparada, como nenhuma época anterior, para o Carnaval de grande estilo, para a mais espiritural gargalhada e exuberância momesca, para a altura tanscndencental da suprema folia e derrisão aristofânica do mundo. (NIETZSCHE 2005, p. 114s.) 
Ironia, eis o nome da derrisão paródica, do pathos da distância, primeiro passo da maiêutica nietzscheana.

Encontramos algo de similar no no romance de Umberto Eco, "O Nome da Rosa", no qual Jorge de Burgos representa o guardião da verdade absoluta que não pode ser desafiada nem mesmo pelo riso - daí a proibição dos textos e imagens cômicas. Os representantes da seriedade, como esse personagem, são também os eternos guardiões da verdadeira fé. Para eles, o supremo perigo representado pelo riso é que este pode tomar conta das pessoas doutas e sérias. Fazer do riso objeto da filosofia e da teologia é uma inversão de valores, que deve ser exemplarmente condenada e punida, daí ser necessária a destruição do tratado de Aristóteles sobre o riso e a comédia. Neste aspecto, a condenação do riso pelo personagem Jorge de Burgos é análoga à objeção platônica contra o mesmo: se no primeiro caso, o riso pode afastar os indivíduos de Deus, no segundo, afasta-os da razão e do caminho da verdadeira sabedoria. Em ambos, o riso é admitido como coisa dos medíocres, de pessoas simples e vulgares, da plebe. Estes, no entanto, não representam o perigo, mas sim os doutos. "A igreja pode suportar a heresia dos simples, que se condenam sozinhos, arruinados por sua ignorância" (NIETZSCHE 2005, p. 455), afirma Jorge de Burgos, mas não a dos doutos.

Pois que o efeito principal do riso é suspender a razão e desarmá-la. O riso também liberta o indivíduo do medo, também do temor do demônio - e se o homem puder rir, quem ou o que o impedirá de afrontar a autoridade instituída e, no limite, o próprio Deus, com o seu riso e sua ironia? Se é verdade que a religião se baseia no medo, então tememos, paradoxalmente, a mesma divindade que ama- 
mos, numa ambivalência que leva à submissão voluntária. Tememos a onisciência divina, que perscruta o âmago da alma e os conhece todas as intenções do coração. Por causa disso, o 'mais feio dos homens', em Assim Falou Zaratustra, é o personagem que mata Deus, pois não consegue suportar a presença daquele que tudo vê, ao qual nada, nunca e em lugar algum, permanece oculto. Assim, se o temor é fundamental, a ironia, ao contrário, cria a ímpia distância a partir da qual pode-se começar a perder o medo, a ver de outra ótica; e, além disso, poder rir; por sua vez, aquele que é capaz de rir, adquire com isso a coragem para não mais temer.

O riso libera o aldeão do medo do diabo, porque na festa dos tolos também o diabo aparece pobre e tolo portanto controlável. Mas este livro poderia ensinar que libertar-se do medo do diabo é sabedoria. Quando ri, enquanto o vinho borbulha em sua garganta, o aldeão sente-se patrão, porque inverteu as relações de senhoria: mas este livro poderia ensinar aos doutos os artifícios argutos, e desde então ilustres, com que legitimar a inversão. Então seria transformado em operação do intelecto aquilo que no gesto irrefletido do aldeão é ainda e afortunadamente operação do ventre. Que o riso é próprio do homem é sinal do nosso limite de pecadores. Mas deste livro quantas mentes corrompidas com a tua tirariam o silogismo extremo, pelo qual o riso é a finalidade do homem! O riso distrai, por alguns instantes, o aldeão do medo. Mas a lei é imposta pelo próprio medo, cujo nome verdadeiro é temor a Deus. E deste livro poderia partir a fagulha luciferina que atearia no mundo inteiro um novo incêndio: e o riso seria designado como arte nova, desconhecida até de Prometeu, para anular o medo. Para o aldeão que rir, naquele momento, não lhe importa morrer: mas depois, acabada sua licença, e a liturgia impõe-lhe de novo, de acordo com o desígnio divino, o medo da morte. E deste livro poderia nascer a nova e destrutiva aspiração a destruir a morte através da libertação do medo. E o que queremos nós, criaturas pecadoras, sem o medo, talvez o mais benéfico e afetuoso dos dons divinos. (NIETZSCHE 2005, p. 455) 
Trata-se, pois, de um ataque ao espírito de gravidade, mas também de uma boa-vontade para brincar com a própria seriedade. Nietzsche chamou a atenção para a proximidade entre a jovialidade e a forma de vida do trovador, do poeta-cantor, que enfrenta com bom ânimo mesmo o perigo mais extremo. Giuliano Campioni reconstitui essa tradição provençal, na qual Nietzsche vê a "unidade entre cantor, cavaleiro e espírito livre" (CAMPIONI 2010, p. 15 37). Para Nietzsche, o pensamento sempre esteve, ao longo de milênios de história cultural, imantado no horizonte normativo da verdade, posta como bem supremo, de origem divina. Esse é o solo onde se firma a raiz moral da vontade de verdade, cujo valor nunca pôde ser questionado, nunca pôde aparecer como um problema.

Nessa problematização do valor da verdade consiste a principal tarefa filosófica que Nietzsche reconhece como seu propriumetipssissimum na história da filosofia: assumir o ponto de vista (Standpunkt) crítico, próprio da modernidade, para, a partir dele, expor o parentesco entre o ideal de veracidade e os valores cardinais da moral vigente, mostrando em que medida e profundidade a ciência moderna, a despeito de seu propalado ateísmo e pretensa neutralidade axiológica, ainda permanece fundamentalmente devota ${ }^{3}$.

Para que possamos nos convencer plenamente de que o problema da origem divina e incondicionada da verdade jamais foi sequer tocado pelo diapasão da crítica filosófica, basta que nos aproximemos, segundo Nietzsche, dos majestosos edifícios teóricos do idealismo alemão - por exemplo,

\footnotetext{
${ }^{3}$ Conferir, a esse respeito, o aforismo 345 do livro V de A Gaia Ciência. KSA, op. cit. p. 237s.
} 
de Kant, Hegel ou Schopenhauer. "Nunca a crítica foi assestada no próprio Ideal, porém apenas no problema: de onde vem a contradição a ele, por que o ideal ainda não foi alcançado, ou por que ele não é demonstrável, em parte ou no todo?" (NIETZSCHE 1980, p. 237s.). Para manter intocável esse ideal, a filosofia moderna, em particular o idealismo alemão, teve de impor limites ao conhecimento científico, justamente para conservar espaço para a fé no valor absoluto do Incondicionado.

O resgate ocorre seja pela subtração do Ideal ao poder corrosivo da crítica, seja pela justificação filosófica de uma 'ordenação moral', ou de uma 'significação ética do universo', ou ainda por meio da interpretação do vir-a-ser como processo histórico de auto consciência e realização do espírito absoluto. Em todas essa variantes, permanece intangível o âmbito incondicionado dos valores morais, mesmo perante o refinado senso histórico que caracteriza a moderna da consciência científica.

Para Nietzsche, entretanto, o sentido histórico constitui uma força nova que, transfigurada em filosofia, abre-se para o reconhecimento de uma nova tarefa, para a urgência a que esta tarefa corresponde. A exigência consiste em aplicar o vigor da crítica histórica ao domínio dos valores morais e às formas tradicionais de avaliação; consiste também no dever de levar até às últimas consequências o escrúpulo rigoroso do historiador, que constitui o legítimo apanágio da modernidade científica - ela própria um fruto e um resultado do devir histórico da vontade de verdade, tal como esta vem à luz especialmente na Aufklärung.

Aprofundar e levar adiante a questão crítica é um imperativo que emana do âmago da consciência histórica, e se 
apresenta,dest'arte, como a forma contemporânea da honestidade intelectual. A missão epocal da consciência proba consistirá em revelar a inevitável parcialidade que atua nos bastidores de toda exigência incondicional - inclusive aquela do valor verdade tomado como absoluto -, expor a injustiça perspectiva, o incontornável viés inerente a toda forma de valoração. Esse retorno a si e contra si é o experimentum crucis da honestidade filosófica, que não teme as consequências lógicas de seus próprios valores, não denega o caráter problemático de toda moral. Esta experiência pode ser descrita como dissolução da moralidade, como o inferno de ver-se convertida no contrário de si mesma, ao ser constrangida, por dever de retidão, a reconhecer a inverdade e a improbidade de qualquer valoração. Pois, do ponto de vista crítico-genealógico, toda moral historicamente existente subsiste apenas como uma determinada perspectiva de interpretação do mundo e da vida e, portanto - na medida em que se afirma como exigência infinita -, como tirania, como violência imposta contra toda a possibilidade de outras, várias morais.

A importância incondicional, o egoísmo cego como qual se trata si mesma toda moral quer que não possa haver muitas morais, ele não quer nenhuma comparação, também nenhuma crítica: apenas fé incondicional em si. Ela é, pois, essencialmente anti científica - e o moralista perfeito deveria ser, já por si mesmo, um amoral (unmoralisch), além de Bem e Mal. (NIETZSCHE 1980, p. 510s.)

Esse testemunho franco, que é também a suprema ironia da consciência moral, a crítica filosófica tem de obtê-lo justamente do estado atual do saber científico. Se o perfeito moralista - responsável pela genealogia e pela crítica histórica da moral - já tem de ser amoral, em virtude de seu 
próprio ofício, (por ter-se compenetrado da 'imoralidade' inerente a todo imperativo de fé incondicional num Ideal moral), então a moderna consciência filosófica não pode mais deixar de reconhecer a injustiça de sua própria moralidade subjacente.

Nessa vertigem, a veracidade é sublimada em probidade intelectual a qualquer custo, guiando-se ainda pelo valor absoluto da verdade, mas para, ao final, também poder zombar de sua própria exigência absoluta. Não existe, para a consciência, nenhuma outra alternativa senão radicalizar suas pretensões, pois que ela própria é formada e nutrida pela seiva das exigências infinitas, dos valores da moral socrático-platônico-cristã. Ora, essa moral, como toda outra, revelou-se, entretanto, tirânica e inverídica, em sua origem; digna de riso em sua pretensão de incondicionalidade: esta é uma descoberta que conduz à maldição da honestidade intelectual, pois não lhe é permitido furtar-se ao seu derradeiro 'tu deves'. Nele - e por ele - deve-se colocar toda moral sob suspeição, abandonar a pátria que essa mesma consciência ainda gostaria de preservar.

Ao passar pela prova de sua honestidade, tomando a si mesma como objeto, a consciência filosófica vê-se, assim, submetida à força irresistível da virtude por ela mesmo gerada, ao seu derradeiro de 'tu deves': o dever de retidão em relação à própria gênese, questão que a obriga a se proibir toda mentira, inclusive a falsa crença na incondicionalidade do ideal de verdade a qualquer preço. Com efeito, esse ideal só vigora como incondicionado por força da crença platônico-cristã na origem divina da verdade; à sombra da morte de Deus - forma suprema da verdade - ele perde toda sustentação. Eis, portanto, o resultado da experiência 
limite que a honestidade intelectual realiza consigo mesma; ela conduz à desterritorialização, à perda do fundamento originário.

A derradeira virtude e o último dever devem ser tomados aqui em duplo sentido: 'último' na acepção em que a probidade intelectual, assim como a incondicional vontade de verdade, acabaram por se revelar, por fim, como sendo a própria crença no ideal moral: "essa vontade, porém, este resíduo de ideal”, comandando no interior da própria ciência, "é, se me quiserem acreditar, aquele ideal mesmo, em sua mais vigorosa, em sua mais espiritual formulação, esotérica de cabo a rabo, despida de todo contraforte e, com isso, não tanto seu resíduo como sua medula" (NIETZSCHE 1974, p. 331).

Mas, em outro sentido, a palavra 'derradeiro' denota o cumprimento de um último 'dever': negar legitimidade e validade incondicional a toda moral, e projetar a virtude para além dela mesma, liberando-a de qualquer reverência a obrigações vinculantes, intangíveis. Onde, em que se fundaria, aliás, um dever categórico, qual seria o substrato da virtude, se todo valor moral (única base de sustentação do dever ser) revelou-se como injustiça e tirania, como o contrário de uma exigência autenticamente moral? Para os 'espíritos muito livres', termos como honestidade intelectual, virtude, moralidade, deixaram de fazer sentido, não valem senão como signos de 'ironia', como fórmulas, ou máscaras, úteis no comércio com aqueles que se mantêm prisioneiros de regras, normas, preceitos e superstições.

Depois que a veracidade cristã tirou uma conclusão depois da outra, ela tira, no fim, sua mais forte conclusão, sua conclusão contra si mesma; isso, porém, acontece quando ela coloca a questão 'e que 
significa toda vontade de verdade'? [...]. E aqui toco outra vez em meu problema, em nosso problema, meus amigos desconhecidos (pois ainda não sei de nenhum amigo): Que sentido teria nosso ser inteiro, senão o de que, em nós, aquela vontade de verdade teria tomado consciência de si mesma como problema? Nesse tomar consciência de si da vontade de verdade vai, de agora em diante - disso não há dúvida nenhuma -, a moral ao fundo" (NIETZSCHE 1974, p. 332).

Para a consciência filosófica, o resultado último não pode ser senão a auto supressão da moralidade; para ela, virtude e dever não significam senão recursos semióticos, dos quais ela não pode abrir mão para a realização de sua tarefa, para a formulação de seu problema: aquele que consiste em revelar como problemático, como digno de questão, o ideal moral da vontade de verdade. Porém, para os próprios 'espíritos muito livres', para 'novos filósofos', amantes do 'perigoso talvez', tais designações não passam de "digna pompa de palavras [...], velho enfeite, quinquilharia e pó dourado de mentiras da inconsciente vaidade humana" (NIETZSCHE 1974, p. 296), sem força cogente, já incapaz de obrigar.

Essa auto supressão da gravidade moral é um paradoxo:

Em que medida a auto destruição da moral é uma parte de sua própria força. Nós europeus temos em nós o sangue daqueles que morreram por sua fé: nós consideramos a moral de modo terrível e sério: e não há nada que não tenhamos, de algum modo, sacrificado a ela. Por outro lado, nossa sutileza espiritual foi alcançada essencialmente por meio da vivissecação da consciência moral. Nós ainda não sabemos para onde somos impelidos, depois de nos termos desligado, dessa maneira, de nosso antigo solo. Mas esse mesmo solo criou em nós a força que agora nos impulsiona para longe, para a aventura pela qual somos lançados no infinito, no não provado, não descoberto - não nos resta nenhuma escolha: temos que ser conquistadores, desde que não temos nenhuma terra que gostaríamos de 'preservar'. 
Não, isso vós o sabeis melhor, meus amigos! O oculto 'sim' em vós é mais forte que todo 'não' e 'talvez', de que são doentes e dependentes vós e vosso tempo; e se tendes de partir para o mar, vós imigrantes, a isso vos obriga uma crença [...]. (NIETZSCHE 1980, p. 168)

Em sentido originário e rigoroso, a ironia, como o riso, é essencialmente subversiva, e atua como potência de transvaloração dos códigos que, a princípio, parece assumir e representar; ela solapa os códigos estabelecidos, operando com a própria simbologia desses códigos. Ironia é a arte de zombar, de provocar, com o objetivo de denúncia e de crítica; sua virtude consistem em levar o leitor a assumir uma postura ativa, exigindo reflexão e tomada de posição. É nesse sentido que a ironia é praticada pelos mestres da zombaria gaiata, como Sócrates, Kierkegaard e Nietzsche.

Ironizar a moral é assumir tão seriamente um 'tu deves' a ponto de sermos tragados por esse dever, na vertigem de um questionamento que não dominamos mais, que leva à indistinção entre autor e personagem: "Nós nos emancipamos do Cristianismo não porque tenhamos vivido muito longe dele, mas porque vivemos muito perto dele, mais ainda, porque crescemos a partir dele - é nossa própria devoção, a mais sincera e mimada, que hoje nos proibe ainda ser cristão."( Id. 2[200], p. 165) Essa perda do solo originário, 'que ainda gostaríamos de preservar', Nietzsche a enuncia como risco e aventura, como um temerário lançar-se ao desconhecido, como uma aposta no infinito. Assumir o risco de afrontar a moral como um problema, é abalar os alicerces da crença na moral, impugnando todo direito a essa crença.

De onde vem a onipotência da fé? Da fé na moral? (Que se denuncia também em que as próprias condições fundamentais da vida são fal- 
samente interpretadas em proveito da moral: apesar do conhecimento do mundo animal e vegetal) [...]. Minha tentativa: compreender os juízos morais como sintoma e linguagem simbólica, nos quais se denunciam as ocorrências do prosperar e fenecer fisiológicos, assim como a consciência das condições de conservação e crescimento: um modo de interpretação do valor da Astrologia. (Id. 2[165], p. 147s.)

Como sintoma e semiótica, toda moral, todo valor incondicional é ridículo; toda perspectiva de valor remete inevitavelmente a condições de conservação, crescimento ou declínio, portanto a um âmbito extra-moral, de nenhum modo incondicional. Daí porque a sacralidade torna-se risível - para os 'bons europeus', homens de boa consciência, herdeiros da milenar devoção cristã-europeia à veracidade, a moral não é mais um dado, mas um ponto de interrogação:

Toda essa velha moral não nos importa mais: não há aí nenhum conceito que ainda mereça respeito. Nós a sobrevivemos - não somos mais suficientemente grosseiros e ingênuos para termos que nos deixar ludibriar dessa maneira [...]. Dito o mais cortesmente: somos muito virtuosos para tanto [...]. E se a verdade, no velho sentido, era 'verdade' somente porque a velha moral dizia sim a ela, podia dizer sim a ela, disso se segue, então, que nós não temos mais também nenhuma verdade de outrora [...]. Nosso kriterium de verdade não é, em absoluto, a moralidade: nós refutamos uma afirmação ao demonstrála dependente da moral, inspirada por nobres sentimentos. (NIETZSCHE 1980, p. 454s.)

Se esses problemáticos herdeiros da moral cristãeuropeia são demasiado virtuosos para ainda prestar ouvidos a qualquer 'lei moral acima de nós', é porque essa moral cumpriu seu destino, e, portanto, foi levada à auto supressão, sucumbindo como todas as outras coisas sérias e veneráveis que existiram sobre a terra: "Todas as grandes coisas sucumbem por si mesmas, por um ato de auto supressão: assim o quer a lei da vida, a lei da necessária auto 
superação que está na essência da vida - sempre esse chamado alcança por último o próprio legislador: pateremlegem, quam ipse tulist."(NIETZSCHE 1974, p. 332)4 A crença no valor absoluto da veracidade, ao final desse percurso irônico, nos obriga a nos tornar imigrantes, e abandonar para sempre o porto seguro da moral, a nos desobrigar do dever de obediência a seus imperativos. Justamente nessa crença se revela como o derradeiro engajamento moral da crítica da moral por Nietzsche, engajamento por ironia: trata-se da esperança na possibilidade do Além-do-Homem, na abertura de novos horizontes para a aventura humana na história, de presságios que se delineiam à sombra terrificante do nihilismo extremo.

Trata-se, pois, fundamentalmente, do modo como se pode vivenciar e fazer a experiência da necessidade extrema: a partir do ponto de vista da indigência, ou do excedente de força, que é capaz de apreende-la com o gume afiado do pensamento crítico. Toda atenção, toda precaução, no entanto, são convocadas precisamente aqui. Nesse ponto é necessário resistir à tentação de sucumbir a uma nova forma de seriedade, aquela que se abriga na força das convicções.

O ermitão não acredita que um filósofo - suposto que um filósofo sempre foi primeiro um ermitão - tenha jamais expresso suas próprias e últimas opiniões em livros: não se escrevem livros, precisamente, para resguardar o que se guarda em si? - ele até duvidará se um filósofo pode, em geral, ter opiniões "últimas e próprias", se nele, por trás de cada caverna, não jaz, não tem de jazer uma caverna ainda mais profunda, um modo mais vasto, mais alheio, mais rico, além de uma superfície, um sem-fundo por trás de cada fundo, por trás de

${ }^{4}$ Tradução ligeiramente alterada. 
cada "fundamento". Cada filosofia é uma filosofia de fachada - eis um juízo ermitão: "Há algo de arbitrário se aqui ele se deteve, olhou para trás, olhou em torno de si, se aqui ele não cavou mais fundo e pôs de lado a enxada - há também algode desconfiado nisso". Cada filosofia esconde também uma filosofia; cada opinião é também um esconderijo, cada palavra também uma máscara (NIETZSCHE 1999, p. 336).

Como o poeta de Pessoa, o filósofo nietzschiano também é um fingidor; se o poeta-filósofo escreve uma Autopsicografia, o filósofo-poeta compõe o seu Ecce Homo, em ambos os casos:

O poeta é um fingidor.

Finge tão completamente

Que chega a fingir que é dor

A dor que deveras sente.

$E$ os que lêem o que escreve,

$\mathrm{Na}$ dor lida sentem bem,

Não as duas que ele teve,

Mas só a que eles não têm.

E assim nas calhas de roda

Gira, a entreter a razão,

Esse comboio de corda

Que se chama coração.

A ironia é o refinamento, mas também a força imponderável de nossa honestidade poética, que é também probidade intelectual, aquela que nos proíbe a farsa das opiniões derradeiras e definitivas, o consolo e a refúgio em todo incondicionado artigo de fé. A potência do riso e da ironia nos protege de nos deixarmos transformar em fanáticos sectários ou em espantalhos moralistas. Poder rir de si mesmo, e, no momento certo, é ser capaz de saber usar o chapéu do palhaço e os guizos do bufão.

Nossa última gratidão para com a arte. - Se não tivéssemos declarado 
boas as artes e inventado essa espécie de culto do não-verdadeiro: a com preensão da universal inverdade e mendacidade, que agora nos é dada pela ciência - a compreensão da ilusão e do erro como uma condição da existência que conhece e que sente -, não teria podido ser tolerada. A lealdade teria o nojo e o suicídio por consequência. Mas agora nossa lealdade tem uma potência oposta, que nos ajuda a desviar tais consequências: a arte como a boa vontade com a aparência. Nem sempre proibimos nosso olho de arredondar, de fingir até o fim: e então não é mais a eterna imperfeição que portamos sobre o rio do vir-a-ser - então pensamos portar uma deusa e somos orgulhosos e infantis nessa prestação de serviço. Como fenômeno estético, a existência é sempre, para nós suportável ainda, e pela arte foi-nos dado olho e mão e antes de tudo a boa consciência para, de nós próprios, podermos fazer um tal fenômeno. Temos de descansar temporariamente de nós, olhando-nos de longe e de cima e, de uma distância artística, rindo sobre nós ou chorando sobre nós: 1 temos de descobrir o her6i, assim como o parvo, que reside em nossa paixão do conhecimento, temos de alegrar-nos vez por outra com nossa tolice, para podermos continuar alegres com nossa sabedoria! E precisamente porque nós, no último fundamento, somos homens pesados e sérios e somos mais peso do que homens, nada nos faz mais bem do que a carapuça de pícaro: nós precisamos usá-la diante de nós próprios - precisamos usar de toda arte altiva, flutuante, dançante, zombeteira, pueril e bem-aventurada, para não perdermos aquela liberdade sobre as coisas que nosso ideal exige de nós. Seria um atraso para nós, precisamente com nossa excitável lealdade, cair inteiramente na moral e, por causa das exigências mais que rigorosas que fazemos a nós quanto a isso, tornar-nos ainda, nós próprios, monstros e espantalhos de virtude. Devemos poder ficar também acima da moral: e não somente ficar, com a amedrontada rigidez de alguém que a cada instante tem medo de escorregar e cair, mas também flutuar e brincar acima dela. Como poderíamos, para isso, prescindir da arte, como do parvo! - E enquanto de algum modo ainda vos envergonhais de vós próprios, ainda não fazeis parte de nós! (NIETZSCHE 1999, p. 181s.).

Com esse segredo Nietzsche conclui Para Além de Bem e Mal. Para ele, se os deuses também filosofam, então está redimida também a potência da gargalhada, pois ela é digna 
dos filósofos e dos deuses. Claramente, é contra Platão que se volta a pointe aqui:

Nenhum deus filosofa ou deseja ser sábio - pois já é -, assim como se alguém mais é sábio, não filosofa. Nem também os ignorantes filosofam ou desejam ser sábios; pois é nisso mesmo que está o difícil da ignorância, no pensar, quem não é um homem distinto e gentil, nem inteligente, que lhe basta assim. Não deseja portanto quem não imagina ser deficiente naquilo que não pensa the ser preciso. (PLATÃO 1983, p. 35).

Os deuses nietzschianos, ao contrário do que pensa a platônica Diotima, são deuses que também filosofam; do mesmo modo como a verdade é mulher, e, como tal, não se deixa conquistar pela pesada seriedade dos ascetas. Dioniso, o deus-tentador, ambíguo, sedutor e bailarino, é filósofo e parceiro de Ariadne; de sua filosofia podemos aprender que o riso não é nenhuma 'grande enfermidade da natureza humana, que toda boa cabeça pensante deveria se esforçar por superar', como pensam os vetustos dogmáticos. Dele aprendemos também que a ironia assegura aos 'espíritos livres' a distância crítica que os protege contra petrificação em convicções derradeiras e definitivas, a tentação dos quixotescos fundamentos inconcussos. Se a ironia de Sócrates desconcertava os atenienses, para despertá-los do sono dogmático, e de uma ignorância ignorante de si própria, a ironia nietzschiana é um expediente para a maiêutica do riso. $\mathrm{O}$ anti-platônico filósofo Dioniso está justamente no cume da hierarquia dos filósofos, e para essa altura ele conduz seu 'último discípulo' - das máscaras que personificam Teseu-Dioniso aprendemos a força irresistível de uma áurea e nada solene gargalhada.

E supondo que também os deuses filosofam, como algumas dedu- 
ções já me fizeram crer, não duvido que eles também saibam rir de maneira nova e sobre-humana - e à custa de todas as coisas sérias! Os deuses gostam de gracejos: parece mesmo que em cerimônias religiosas não deixam de rir (NIETZSCHE 2005, p. 177).

Abstract: Based on the relationship between art and philosophy, as it is treated in Friedrich Nietzsche's thought, the article develops a reflection on the seriousness and the laughter, the lightness and the gravity, to emphasize the importance of irony and humor in the criticism of Nietzsche to metaphysics and morality. In this sense we try to present and discuss how Nietzsche develops an irony of a special kind, the expedient for a "maieutic of laughter". This irony is what assures the 'free spirits' of the critical distance that protects them against petrification in ultimate convictions and the temptation of established foundations.

Keywords: Art; philosophy; moral; irony.

\section{REFERÊNCIAS}

CAMPIONI, Giuliano. „Gaya Scienza“ und „Gai Saber“; in Nietzsches Philosophie. In: PIAZZESI, Chiara u. a. (Hg.): Letture della Gaia scienza. Pisa 2010 [Nietzscheanasaggi 14], S. 15-37.

DUVAL, R. Nietzsche et le platonisme. In: Revue des Sciences Philosophiques et Théologiques, tome LIII, n. 4, octobre. Paris: J Vrin, 1969.

. A Gaia Ciência. I, 1. Trad. Paulo César de Souza. São Paulo: Companhia das Letras, 2001.

. A Gaia Ciência, aforismo § 107. In: Obra Incompleta. Trad. Rubens Rodrigues Torres Filho. Coleção Os Pensadores, São Paulo: Editora Nova Cultural, 1999.

. Além de Bem e Mal. Trad. Paulo César de Souza. São Paulo: Companhia das Letras, 2005. 
. Assim Falou Zaratustra. Trad. Paulo César de Souza. São Paulo: Companhia das Letras, 2011.

- Genealogia da Moral. Trad. Paulo César de Souza. São Paulo: Companhia das Letras, 1998.

. Para a Genealogia da Moral III, 27. In: Obras Incompletas. Trad. Rubens Rodrigues Torres Filho. $1^{\mathrm{a}}$ ed. Coleção Os Pensadores, São Paulo: Abril Cultural, 1974.

. Sämtliche Werke. Kritische Studienausgabe (KSA). Ed. G. Colliund M. Montinari. Berlin, Ney York, München: de Gruyter/DTV. 1980.

PLATÃO. A República. Tradução de Carlos Alberto Nunes. Belém: Editora Universidade Federal do Pará, 1988.

. O Banquete, 204 a. Trad. José Cavalcante de Souza. Coleção Os Pensadores, 2a. Ed. São Paulo: Abril Cultural, 1983. 